\title{
Switching of NMDA Receptor 2A and 2B Subunits at Thalamic and Cortical Synapses during Early Postnatal Development
}

\author{
Xiao-Bo Liu, ${ }^{\star}$ Karl D. Murray, ${ }^{\star}$ and Edward G. Jones \\ Center for Neuroscience, University of California, Davis, California 95616
}

\begin{abstract}
Switching of the NMDA receptor 2A (NR2A) and NR2B subunits at NMDA receptors is thought to underlie the functional changes that occur in NMDA receptor properties during the developmental epoch when neural plasticity is most pronounced. The cellular expression of NR2A and NR2B and the NR2 synaptic binding protein postsynaptic density-95 (PSD-95) was examined in the mouse somatosensory cortex and thalamus from postnatal day 2 (P2) to P15 using reverse transcription-PCR, in situ hybridization histochemistry, and immunocytochemistry. The localization of NR2A and NR2B subunits and PSD-95 was then studied at synapses in layer IV of somatosensory cortex and in the ventral posterior nucleus of the thalamus using high-resolution immunoelectron microscopy. At both cortical and thalamic synapses, a quantitative switch in the dominant synaptic subunit from NR2B to NR2A was accompanied by a similar change in the cellular expression of NR2A but not of NR2B. Synaptic PSD-95 developed independently, although both NR2A and NR2B colocalized with PSD-95. Displacement of NR2B subunits from synapses was not accompanied by an increase in an extrasynaptic pool of this subunit. Thus, the switch in synaptic NR2 subunit predominance does not occur by changes in expression or displacement from synapses and may reflect the formation of new synapses from which NR2B is lacking.
\end{abstract}

Key words: plasticity; glutamate receptors; immunogold; thalamocortical; synaptic transmission; mRNA

\section{Introduction}

Proper nervous system function depends critically on appropriate development and maturation of synaptic connections. The mechanisms underlying these processes are uniquely sensitive to manipulations during early postnatal development. Limiting sensory activity during this "critical" period skews the distribution of synaptic inputs in favor of remaining, more active connections (Bear et al., 1990; Li et al., 1994; Kutsuwada et al., 1996; Iwasato et al., 1997; Rema et al., 1998; Roberts and Ramoa, 1999). Excitatory glutamatergic transmission, governed by the NMDA receptor (NMDAR), has been implicated in this process (Katz and Shatz, 1996; Crair, 1999). NMDARs dominate glutamatergic transmission in early development, and pharmacological or genetic blockade of NMDAR function prevents normal formation and plasticity of sensory maps (Schlaggar et al., 1993; Li et al., 1994; Iwasato et al., 1997). Despite a central role in synaptic refinement, the molecular basis for this NMDA-dependent malleability is not known.

During early postnatal development, coincident with the critical period, the characteristics of NMDAR-mediated synaptic

\footnotetext{
Received June 22, 2004; revised Aug. 18, 2004; accepted Aug. 31, 2004.

This study was supported by National Institutes of Health-United States Public Health Service Grant NS21377. We thank Phong Nguyen for technical assistance.

${ }^{*}$ X.-B.L. and K.D.M. contributed equally to this work

Correspondence should be addressed to Dr. Edward G. Jones, Center for Neuroscience, University of California, Davis, CA 95616. E-mail: ejones@ucdavis.edu.

DOI:10.1523/JNEUROSCI.2476-04.2004

Copyright $\odot 2004$ Society for Neuroscience $\quad$ 0270-6474/04/248885-11\$15.00/0
}

transmission are dramatically altered, raising the possibility that the NMDAR itself is a substrate of activity-dependent plasticity (Constantine-Paton and Cline, 1998; Quinlan et al., 1999b; CullCandy et al., 2001; Townsend et al., 2003). Functional NMDARs are heteromeric complexes, permissive for calcium, and composed of at least one obligatory NMDA receptor 1 (NR1) subunit and one or more NR2A-D subunits, the presence of which modulates channel functional properties (McBain and Mayer, 1994; Wenthold et al., 2003). Another subunit, NR3A, was recently characterized in association with neuronal development and also influences NMDAR channel function (Sucher et al., 1995; Wong et al., 2002). Shortly after birth, cortical neurons display relatively large and long-duration NMDAR-mediated EPSCs (Flint et al., 1997; Barth and Malenka, 2001; Lu et al., 2001). However, during the early critical period of postnatal development, the decay kinetics of the NMDAR becomes faster, resulting in much shorter EPSCs (Barth and Malenka, 2001; Lu et al., 2001; Townsend et al., 2003). These changes are accompanied by a decline in the ability of the specific NR2B antagonist ifenprodil to inhibit NMDAR function (Barth and Malenka, 2001; Lu et al., 2001). This is consistent with a developmental change in the composition of the NMDAR from predominantly NR1/NR2B to NR1/NR2A and is supported by a well-documented developmental increase in the expression of NR2A. Both the kinetics and the pharmacological profile of NMDAR activation during the critical period are sensitive to sensory manipulations (Feldman and Knudsen, 1998; Quinlan et al., 1999a,b), suggesting that perturbations that induce neuronal plasticity do so by affecting the nature of the NMDAR complex at central synapses. 
It has been assumed that the developmental shortening of NMDAR EPSCs is mediated by an exchange of synaptic NR2B for NR2A, but this has not been directly confirmed. Moreover, transgenic mice devoid of NR2A do not exhibit a developmental change in NMDAR biophysical properties but exhibit normal synaptic plasticity in barrel cortex (Lu et al., 2001). Thus, the central role of NMDAR in early developmental plasticity has been called into question. Despite a shortening of the NMDAR current and a decrease in ifenprodil sensitivity during early development, expression of NR2B remains relatively high (Zhong et al., 1995; Stocca and Vicini, 1998), raising the possibility that new synapses rich in NR2A are added to those in which NR2B subunits predominate instead of switching subunits. We combined RNA and protein analysis of NR2A and NR2B subunit expression with high-resolution immunogold electron microscopy (EM) to reveal and quantify the "cellular" and synaptic localization of these subunits during early postnatal development in the mouse somatosensory system. Because postsynaptic density-95 (PSD-95), a major constituent of the postsynaptic density, has been implicated in anchoring and stabilizing NMDARs at synapses (Sheng and Sala, 2001; Wenthold et al., 2003), we examined its developmental and synaptic expression. Part of the study has been published in abstract form (Liu et al., 2002).

\section{Materials and Methods}

Tissue preparation. ICR mice (Harlan Sprague Dawley, Indianapolis, IN) within the ages of postnatal day 2 (P2) to adulthood (P32 or older) were used. All protocols were approved by the Institutional Animal Care and Use Committee. Animals were deeply anesthetized by hypothermia (P2P4) or by an overdose of Nembutal (after P4). For light microscopy, animals were perfused through the heart with cold saline followed by $4 \%$ paraformaldehyde in $0.1 \mathrm{~m}$ phosphate buffer, $\mathrm{pH}$ 7.4. After removal, the brains were cryoprotected in $30 \%$ sucrose in $0.1 \mathrm{~m}$ phosphate buffer. Serial frontal sections through the brain were cut at 10 or $25 \mu \mathrm{m}$ on a freezing microtome and collected in ice-cold $4 \%$ paraformaldehyde solution for in situ hybridization histochemistry or in ice-cold $0.1 \mathrm{M}$ phosphate buffer for immunocytochemical staining. For electron microscopy, animals were perfused through the heart with cold saline followed by $4 \%$ paraformaldehyde plus $0.1-0.15 \%$ glutaraldehyde in $0.1 \mathrm{M}$ phosphate buffer, $\mathrm{pH}$ 7.4. The brain was blocked and cut on a vibratome at $500 \mu \mathrm{m}$. Under a dissecting microscope, small pieces of tissue containing the somatosensory cortex or the ventroposterior (VP) nucleus of the thalamus were excised with a sharp blade and stored in ice-cold $0.1 \mathrm{M}$ phosphate buffer.

In situ hybridization histochemistry. Sections from brains at different postnatal ages (P2, P4, P7, P9, P12, and P15) were processed simultaneously for in situ hybridization histochemistry using antisense RNA probes specific for NR2A and NR2B subunits. Probes were transcribed from rat cDNAs corresponding to nucleotides 1585-2154 (NR2A) and 1423-1992 (NR2B) of the published sequences (Akbarian et al., 1996; Munoz et al., 1999). All probes were labeled by in vitro transcription with $\alpha-{ }^{33} \mathrm{P}$. Sections were incubated in hybridization solution containing $10^{4}$ $\mathrm{cpm} / \mu \mathrm{l}$ antisense RNA probes overnight at $60^{\circ} \mathrm{C}$. The following day, sections were sequentially washed in the following solutions: $4 \times$ SSC at $60^{\circ} \mathrm{C}$ twice for $30 \mathrm{~min}$ each; ribonuclease $\mathrm{A}(0.02 \mathrm{mg} / \mathrm{ml}$ in $0.01 \mathrm{M}$ Tris $\mathrm{HCl}$ buffer, $\mathrm{pH} 8.0$, and $1 \mathrm{~mm}$ EDTA, $2.9 \% \mathrm{NaCl}$ ) at $45^{\circ} \mathrm{C}$ for $1 \mathrm{hr} ; 2 \times$ SSC at room temperature, twice, for 30 min each. Finally, sections were mounted on gelatin-coated glass slides and exposed to Amersham $\beta$-Max autoradiographic film for $2-10 \mathrm{~d}$ at $4^{\circ} \mathrm{C}$ (Amersham Biosciences, Piscataway, NJ). As controls, sense strand-specific RNA probes were generated for each gene and hybridized to adjacent sections.

Film autoradiographs were quantified by densitometry using a microcomputer imaging device (MCID/M6; Imaging Research, St. Catharine's, Ontario, Canada). Probe variability was minimized by simultaneously processing sections from each postnatal age analyzed. Optical density readings were taken from superficial and deep layers of the cortex and from the VP nucleus. Sampling from white matter served as a measure of background hybridization. Optical density readings were converted to levels of radioactivity per unit weight by reference to ${ }^{14} \mathrm{C}$ standards exposed on the same sheet of film. For each probe, in each area, optical density values were expressed as mean \pm SD. Sampled areas were plotted as a function of postnatal age. Direct comparisons of label intensity for different probes were made in the same experimental run. Differences in label intensity between postnatal ages were analyzed by ANOVA, and a $p$ value $\leq 0.01$ was considered significantly different. No hybridization was detected on sections incubated with sense RNA probes (data not shown).

Reverse transcription-PCR. Total RNA was isolated from fresh brains at different postnatal ages ( $\mathrm{P} 2, \mathrm{P} 4, \mathrm{P} 7, \mathrm{P} 9, \mathrm{P} 12, \mathrm{P} 15$, and $\mathrm{P} 40)$. Brain regions including somatosensory cortex and VP nucleus of the thalamus were dissected, mechanically homogenized, and lysed in guanidium isothiocyanate buffer; RNA was column purified according to the directions of the manufacturer (Qiagen, Valencia, CA). After DNase I digestion, cDNA was prepared from $200 \mathrm{ng}$ of total RNA using an oligo (dT) 18 primer and Moloney murine leukemia virus reverse transcriptase (Clontech, Palo Alto, CA). Subsequent PCR were performed using $4 \%$ of the cDNA product as starting material.

Generation of PCR products was measured in real time by incorporation of the fluorescent dye SYBR Green I using a Bio-Rad iCycler realtime PCR machine (Bio-Rad, Hercules, CA). For each reaction, a master mix of the following was made: $1 \times$ PCR buffer (Qiagen), $400 \mathrm{~mm} \mathrm{dNTP \text {, }}$ $0.5 \mathrm{~mm}$ forward and reverse primers (Qiagen Operon, Alameda, CA), $0.01 \times$ SYBR Green I (Molecular Probes, Eugene, OR), $1.5 \mathrm{~mm} \mathrm{MgCl}_{2}, 10$ nM FITC (Bio-Rad), and $1 \mathrm{U}$ of TaqDNA polymerase (Qiagen). PCR products of $\sim 250 \mathrm{bp}$ were generated using the following primers: NR2A sense (5'-CAACGAAGGGATGAATGTGA-3'), NR2A antisense (5'ACAAAGGGCACGGAGAAGT-3'), NR2B sense (5'-TGCTACAACACCCACGAGAA-3'), and NR2B antisense ( $5^{\prime}$-CTCCTCCAAGGTAACGATGC- $\left.3^{\prime}\right)$. All PCRs were performed using the cycle conditions, $94^{\circ} \mathrm{C}(15 \mathrm{sec}), 60^{\circ} \mathrm{C}(30 \mathrm{sec}), 72^{\circ} \mathrm{C}(30 \mathrm{sec})$, and were run for a total of 40 cycles. After PCR, a first derivative melting curve analysis was performed to confirm the specificity of the PCR. In addition, samples from the PCRs were subjected to electrophoresis, purified, and sequenced to verify product identity. The relative expression of mRNAs between samples was calculated by identifying the threshold cycle $(\mathrm{Ct})$ at which product initially appeared above background and calculating the expression level relative to a standard curve generated by serial dilutions of previously purified PCR products.

Western blot analysis. Animals with ages that matched those used for in situ hybridization and immunocytochemistry were decapitated, and their brains were rapidly removed to ice-cold $0.1 \mathrm{~m}$ phosphate buffer. Portions of somatosensory cortex were isolated and homogenized on ice in lysis buffer ( $150 \mathrm{~mm} \mathrm{NaCl}, 20 \mathrm{~mm}$ Tris-Cl, 2 mM EDTA, $1 \%$ Triton X-100, 0.05\% SDS, 1 mm PMSF, pH 8) with Complete Protease Inhibitor Cocktail (Roche, Indianapolis, IN) using a Brinkman Polytron $(2 \times 20$ sec pulses). Tissue homogenates were centrifuged $\left(8000 \times g, 10 \mathrm{~min}, 4^{\circ} \mathrm{C}\right)$, and the supernatants were aliquoted and frozen $\left(-80^{\circ} \mathrm{C}\right)$ for later use.

Protein content was estimated using the Bradford Reagent (SigmaAldrich, St. Louis, MO). Equal amounts of total protein $(10 \mu \mathrm{g})$ were resolved by $12 \%$ SDS-PAGE and electroblotted onto polyvinylidene difluoride membrane (Amersham Biosciences). Membranes were blocked in TBSTw (140 mm NaCl, 3 mm KCl, 25 mm Tris, 0.05\% Tween 20, pH 7.4) containing $10 \%$ evaporated milk and then incubated in primary antibody in TBSTw $/ 5 \%$ milk overnight at $4^{\circ} \mathrm{C}$. Antibody dilutions were as follows: 1:1000 for NR2A (rabbit polyclonal antibody; Upstate Biotechnology, Waltham, MA); 1:1000 for NR2B (rabbit polyclonal antibody; Chemicon, Temecula, CA), and 1:20,000 for $\beta$-actin (a mouse monoclonal antibody; Sigma-Aldrich). After incubation in the primary antibodies, membranes were washed in TBSTw and incubated in TBSTw/5\% milk containing horseradish peroxidase-conjugated secondary antibodies (1:2000; Chemicon) for $1 \mathrm{hr}$ at room temperature. After a brief wash in TBSTw, protein bands were detected using the ECL-plus chemiluminescent reagent (Amersham Biosciences). Densitometric analysis of positive immunostaining was measured using a STORM phosphoimaging system (Amersham Biosciences). 

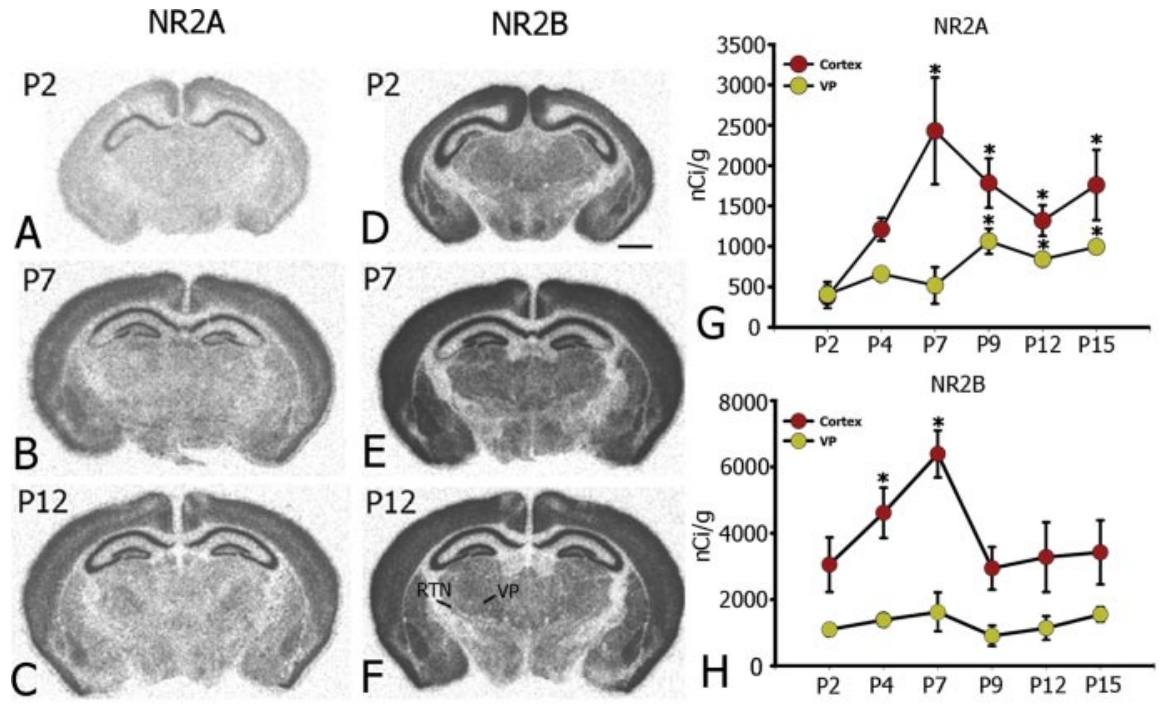

NR2A cortex
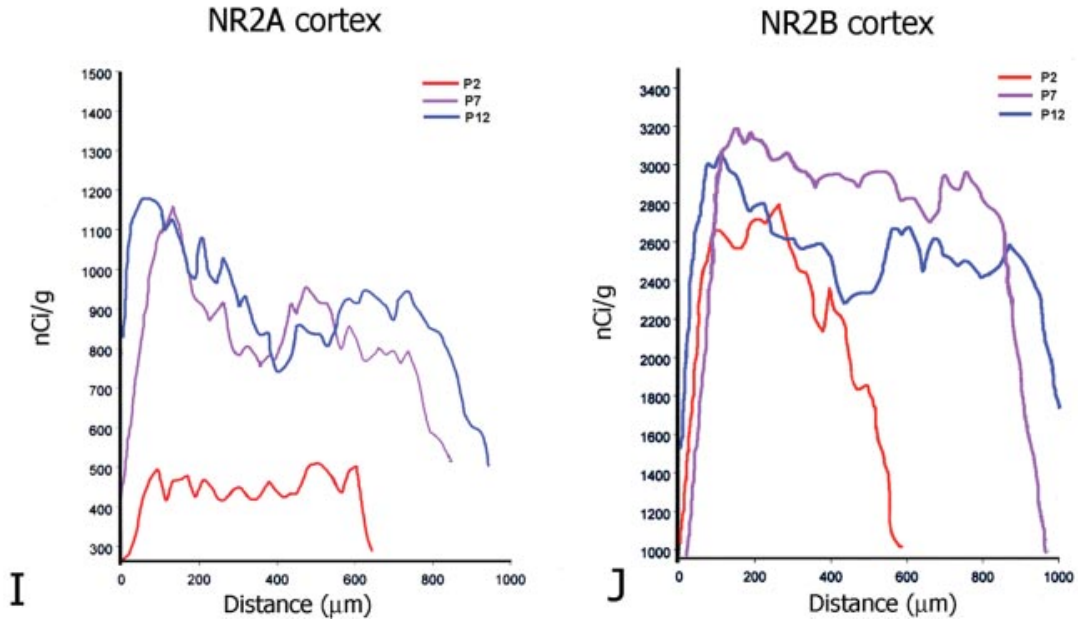

Figure 1. Film autoradiograms from frontal sections through mouse forebrain at $P 2, P 7$, and $P 12$ showing hybridization of ${ }^{33}$ P-labeled RNA probes for NR2A $(A-C)$ and NR2B $(D-F)$ mRNAs. $A-C$, NR2A expression is low in most regions of the forebrain at P2 $(A)$ but substantially increases at later ages $(B, C) \cdot D-E$, In contrast, NR2B mRNA is highly expressed at $P 2(D)$ and remains at or above this level through P12 (F). Scale bar, $0.5 \mathrm{~mm}$. $G, H$, Densitometric measures of film autoradiograms from a typical experiment show statistically significant increases in cortical NR2A mRNA at P7, P9, P12, and P15 compared with P2 (ANOVA; ${ }^{*} P \leq$ 0.0001 ) (G) and significant increases in cortical NR2B mRNA only at P4 and P7 $(H)$ compared with P2 (ANOVA; ${ }^{*} \leq \leq 0.0001$ ). Density readings were obtained from somatosensory cortex and VP nucleus and were calibrated by reference to ${ }^{14} \mathrm{C}$ standards exposed on the same sheet of film. All values are means \pm SDs. I,, , Developmental changes in cortical layer-specific NR2A $(I)$ and NR2B ( $/$ ) mRNA expression measured along the radial axis from pia surface to white matter of somatosensory cortex at $\mathrm{P} 2$ (red lines), P7 (purple lines), and P12 (blue lines). Although changes in NR2B are not observed at P9, P12, and P15, NR2A hybridization increases dramatically with some preference for superficial cortical layers during early postnatal development.

Immunocytochemistry. Specific antibodies to NR2A, NR2B, and PSD-95 were used for immunocytochemical staining. Sections from animals at various postnatal ages (P2, P4, P7, P9, P12, P15, and P25) were simultaneously processed for immunofluorescent or immunoperoxidase staining. Sections were incubated in normal blocking serum for $1-2 \mathrm{hr}$ at room temperature and then transferred to the following primary antibodies: NR2A, NR2B (rabbit polyclonal antibodies diluted 1:500 to 1:1000; Chemicon), and PSD-95 (mouse monoclonal antibody diluted 1:400; Affinity, Golden, CO). Sections were incubated in primary antibodies for $48 \mathrm{hr}$ at $4^{\circ} \mathrm{C}$ and in appropriate secondary antibodies for $1-2 \mathrm{hr}$ at room temperature. For immunoperoxidase labeling, biotinylated secondary antibodies were used (diluted 1:100 to 1:150; Vector Laboratories, Burlingame, $\mathrm{CA}$ ), followed by the $\mathrm{ABC}$ reaction (Vector Laboratories), and immunolabeling was visualized with diaminobenzidine. Sections were mounted on gelatin-coated glass slides and coverslipped with DPX (a mixture of distyrene, tricresyl phosphate, and xylene) mounting medium (BDH, Poole, UK).
To characterize neurons that were PSD-95 immunopositive, some sections were processed for double immunofluorescent labeling using PSD-95 and GABA-specific antibodies. Sections were incubated overnight at $4^{\circ} \mathrm{C}$ in a mixed solution containing PSD-95 (1:400, mouse monoclonal antibody; Affinity) and GABA (rabbit polyclonal antibody, 1:2000; Sigma) primary antibodies. After several washes, sections were incubated in fluoresceinconjugated horse anti-mouse secondary antibody (Vector Laboratories) and Cyanine 5 (Cy5)-conjugated donkey anti-rabbit secondary antibody (Molecular Probes) for $1 \mathrm{hr}$ at room temperature and examined with an Olympus Fluoview laser confocal microscope. Control experiments in which the primary or secondary antibodies were omitted revealed only background staining (data not shown).

Low temperature cryoembedding and postembedding immunogold electron microscopy. Blocks from P2, P4, P7, P9, P15, P19, and P32 cortex and thalamus were cryoprotected by immersion in increasing concentrations of glycerol at $4^{\circ} \mathrm{C}$, plunged into propane cooled to $-180^{\circ} \mathrm{C}$ by liquid nitrogen in a Reichart KF80 cryofixing unit (Leica, Wien, Austria), transferred to the precooled chamber $\left(-90^{\circ} \mathrm{C}\right)$ of a Leica Automatic Freeze Substitution cryoembedding unit, and infiltrated in a $1.5 \%$ uranyl acetate/methanol solution at $-90^{\circ} \mathrm{C}$ for $30 \mathrm{hr}$. The blocks were then embedded in Lowicryl HM-20 (Electron Microscopy Sciences, Fort Washington, PA) and polymerized with ultraviolet light for $60 \mathrm{hr}$ at $0^{\circ} \mathrm{C}$ (Liu et al., 2001).

Serial ultrathin sections $(70-80 \mathrm{~nm})$ containing layer IV of the somatosensory cortex or VP nucleus of the thalamus were mounted on Formvar-coated, single-slot nickel grids and processed for postembedding immunogold labeling. Sections were incubated in $2 \%$ swine albumin in TBST solution ( $5 \mathrm{~mm}$ Tris buffer containing $8 \mathrm{~mm} \mathrm{NaCl}$ and $0.1 \%$ Triton $\mathrm{X}-100$ ) and then transferred to TBST containing primary antibodies for NR2A (1:100 to 1:500; Chemicon), NR2B (1:100 to 1:500; Chemicon), or PSD-95 (a goat polyclonal antibody diluted 1:100, Santa Cruz Biotechnology, Santa Cruz, CA; or a monoclonal antibody diluted 1:400, Affinity) for $4-12 \mathrm{hr}$ at room temperature. After rinsing in TBST, sections were incubated in secondary Fab fragments coupled to $10 \mathrm{~nm}$ gold particles (BBInternational, Cardiff, UK), diluted 1:20 in TBST for $2 \mathrm{hr}$ at room temperature. For double immunogold labeling, grids were incubated in a mixture of horse anti-mouse (PSD-95, $10 \mathrm{~nm}$ gold particles) and goat anti-rabbit (NR2A or NR2B, 15 or $20 \mathrm{~nm}$ gold particles) secondary antibodies. Grids were lightly stained with uranyl acetate and lead citrate and examined in a Philips (Eindhoven, The Netherlands) CM120 electron microscope at $80 \mathrm{kV}$. Electron micrographs were taken either at $20,000 \times$ using a conventional camera or digitally by a $2 \mathrm{~K} \times 2 \mathrm{~K} \mathrm{CCD}$ camera (Gatan, Pleasanton, CA) attached to the electron microscope and processed using DigitalMicrograph software (Gatan). Original electron microscopic negatives were scanned in a Nikon (Tokyo, Japan) Film Scanner LS-4500AF at 2000 dpi. All digitized images were processed and composed in Photoshop 6.0 (Adobe Systems, San Jose, CA). For immunogold quantitative analysis, images showing labeled synapses were adjusted to a final magnification of 70,000 $\times$.

Quantification of immunolabeled synapses. The methods used to quantify immunogold-labeled EM samples have been reported previously 
(Matsubara et al., 1996; Liu et al., 2001). The criteria for inclusion to count labeled synapses were as follows: (1) a clear presynaptic and postsynaptic membrane, (2) a clear PSD, (3) at least one gold particle localized within $20 \mathrm{~nm}$ of the plasma membrane, and (4) at least one gold particle localized between 20 and $500 \mathrm{~nm}$ of the PSD edge. Synaptically localized immunogold particles were counted if they were within 20 $\mathrm{nm}$ of the PSD and could be detected in at least two serial sections. An extrasynaptically localized gold particle was counted if it matched the criteria above, was not localized to the PSD, and could be detected in at least two serial sections. At each postnatal age, for each antibody, and in each region analyzed (layer IV of the cortex and VP nucleus of the thalamus), $\sim 100$ immunolabeled synapses were selected for quantitative analysis. These synapses were pooled from three to five animals at each age. The mean number of immunogold particles per synapse was calculated by dividing the total number of synapse-localized gold particles by the total number of PSD profiles examined and expressed as mean $\pm \mathrm{SD}$. The mean number of gold particles per synapse was plotted as a function of postnatal age. Student's $t$ test was applied to determine whether statistical significance was reached $(p \leq 0.05)$.

\section{Results}

NR2A and NR2B mRNA expression in developing cortex and thalamus

In situ hybridization histochemistry using RNA probes for NR2 mRNAs revealed unique expression patterns for NR2A and NR2B subunits during the first 2 weeks of postnatal life (P2-P15). Each probe displayed a similar trend of developmental changes in repeated experiments $(n=4)$. At the earliest time point examined, P2, hybridization to NR2A mRNA was only slightly higher than background and was mainly detected in the most superficial region of the developing cortex (Fig. 1A). Hybridization levels in the thalamus at this age were below detection. From P4 to P7, hybridization to NR2A mRNA dramatically increased. Densitometric analysis demonstrated that the labeling intensity was more than sixfold higher in cortex at P7 compared with P2 (P2, $377 \pm$ $183 \mathrm{nCi} / \mathrm{gm}$; P7, $2430 \pm 661 \mathrm{nCi} / \mathrm{gm}$ ) (Fig. 1G). By P9 and P12, NR2A labeling throughout cortex had declined slightly but remained significantly increased through P15 (P2, $377 \pm 183 \mathrm{nCi} /$ gm; P15, $1762 \pm 437 \mathrm{nCi} / \mathrm{gm} ; n=8$; $\operatorname{ANOVA}, F_{(5,42)}=40.686$; $p \leq 0.0001$ ) (Fig. $1 A-C, G$ ). A similar developmental increase in expression of NR2A mRNA was observed in thalamus. NR2A mRNA levels were significantly higher at P9 compared with P2 in VP nucleus (P2, $407 \pm 102 \mathrm{nCi} / \mathrm{gm} ; \mathrm{P} 9,1065 \pm 157 \mathrm{nCi} / \mathrm{gm} ; n=$ 4 ; ANOVA, $p \leq 0.0001)$ and maintained this pattern through P15 (Fig. $1 A-C, G$ ).

In contrast to NR2A expression, NR2B mRNA was highly expressed in all layers of the cortex at P2 and remained so through P15. Except for a transient twofold significant increase in expression from P2 to P7 (P2, $3053 \pm 824 \mathrm{nCi} / \mathrm{gm} ; \mathrm{P} 7,6390 \pm 708$ $\mathrm{nCi} / \mathrm{gm} ; n=16$; ANOVA, $\left.F_{(5,106)}=39.081 ; p \leq 0.0001\right)$, hybridization to NR2B mRNA did not significantly change through P15 $(\mathrm{P} 2,3053 \pm 824 \mathrm{nCi} / \mathrm{gm} ; \mathrm{P} 15,3422 \pm 968 \mathrm{nCi} / \mathrm{gm} ; n=16$; ANOVA, $p=0.2$ ) (Fig. $1 D-F, H$ ). Initially, at P2 and P4, expression of NR2B mRNA in the thalamus as a whole was stronger than that of NR2A, as confirmed by densitometry, and was

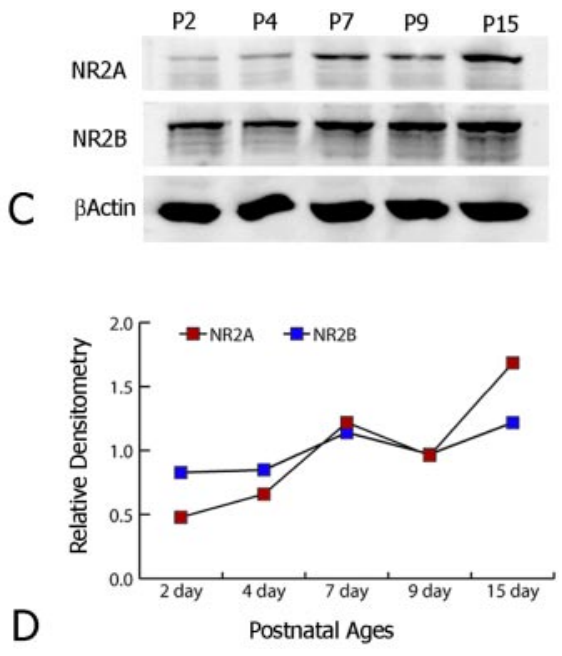

D

Postnatal Ages

Figure 2. Assessment of NR2A and NR2B expression in somatosensory cortex by RT-PCR $(A, B)$ and Western blot analysis $(C, D)$. W at $\mathrm{P} 2$ but undergoes a rapid increase in expression from $\mathrm{P} 4$ to $\mathrm{P} 12$ and maintains this elevated expression through $\mathrm{P} 40$. In

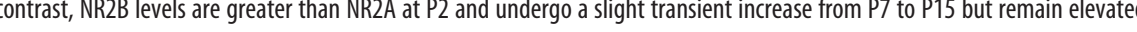
dramatic increase in total cellular protein expression compared with NR2B, for which protein levels remain relatively constant velopment.

slightly higher in VP nucleus (Fig. $1 H$ ). At later ages, P7, P9, P12, and P15, whereas NR2A expression rose in VP nucleus, hybridization to NR2B remained unchanged in VP nucleus (Fig. $1 \mathrm{H}$ ).

The developmental changes in NR2A and NR2B mRNA expression were confirmed by reverse transcription (RT)-PCR. Because of limitations in the quantity of VP tissue available, we focused on somatosensory cortex. NR2A expression at P2 was low, but from P2 to P9, there was a large increase in NR2A mRNA expression. By P12, levels of NR2A mRNA had risen almost 50fold compared with P2 (Fig. 2A). The difference in the fold change between in situ hybridization histochemistry and realtime RT-PCR probably reflects the higher sensitivity of the latter. This high level of expression was maintained at least through P15. In contrast, at P2, levels of NR2B mRNA were sevenfold higher than those of NR2A mRNA (Fig. 2A). From P2 to P7, NR2B mRNA levels rose slightly followed by a rapid increase through P9, after which levels of NR2B mRNA remained stable through P15 (Fig. 2A).

\section{Developmental changes in NR2A and NR2B protein expression}

Tissues were collected at different postnatal ages and processed for Western blot analysis. Because of the small size of the VP region, we concentrated on somatosensory cortex. Developmental changes in NR2A and NR2B protein levels were consistent with changes in mRNA expression. NR2A protein levels were low at P2 but increased more than threefold by P15 (Fig. 2C,D). In contrast, NR2B protein levels were relatively high at P2 and increased only slightly through $\mathrm{P} 7$, after which levels remained stable through P15 (Fig. 2C,D).

The cellular expression pattern of NR2 protein was determined by immunocytochemistry. NR2A and NR2B immunostained neurons were widely distributed throughout the somatosensory cortex and thalamus, including the VP nucleus. 

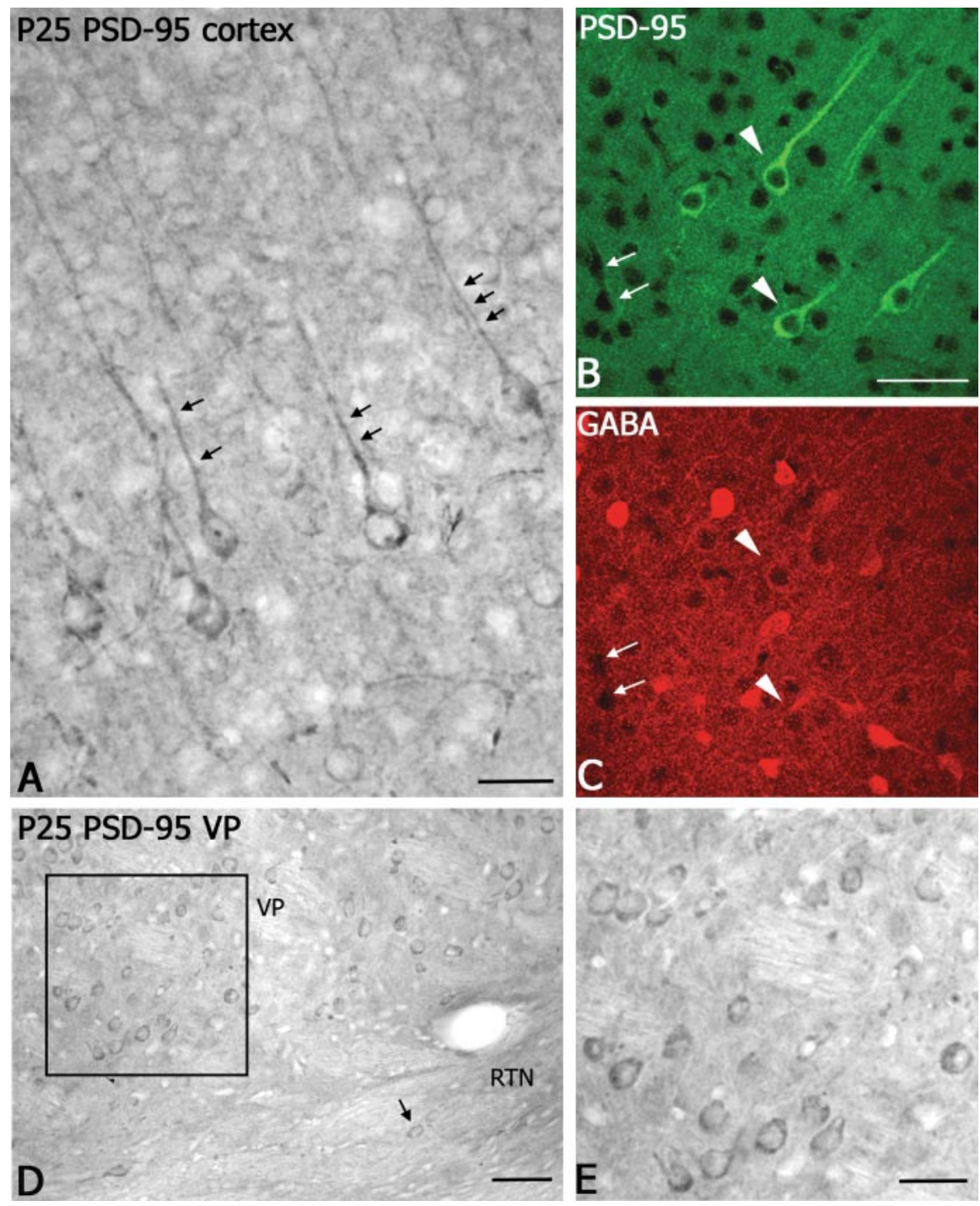

Figure 3. Immunocytochemical localization of PSD-95 in the cortex and thalamus. $A$, In somatosensory cortex, prominent PSD-95 immunoperoxidase-labeled pyramidal neurons are present in layer V. Note the strong immunolabeled apical dendrites (small black arrows). Scale bar, $50 \mu \mathrm{m}$. B, C, Laser confocal microscopic images of double immunofluorescent labeling for PSD-95 ( $B$, green, fluorescein) and GABA ( $C$, red, $C y 5)$ show a lack of colocalization in the cortex (white arrowheads). As a point of reference, small white arrows indicate blood vessels in the section. Scale bar, $60 \mu \mathrm{m}$. D, Light micrograph showing PSD-95 immunoperoxidase labeled neurons in VP; a few labeled neurons are visible in RTN (small arrow). Scale bar, $100 \mu \mathrm{m}$. E, Higher-magnification image of PSD-95-immunolabeled neurons in VP nucleus ( $D$, boxed region). Scale bar, $50 \mu \mathrm{m}$.

Developmental changes in immunocytochemical staining for NR2A and NR2B paralleled those determined by Western blot analysis (data not shown).

\section{Developmental changes in PSD-95 expression}

Western blot analysis showed that, like NR2A, PSD-95 protein levels were low at P2 and then gradually increased after P4 (data not shown). However, unlike NR2A, PSD-95 expression did not change substantially after P7. At P2, PSD-95 immunostaining was diffuse throughout the cortex and thalamus, and no clearly identifiable cell bodies were stained. By P4, immunolabeled cell bodies could be found in both superficial and deep layers of the developing cortex, along with the diffuse pattern seen earlier in the cortex at P4. Some lightly labeled neurons were found in the thalamus as well. After P7, labeled cell bodies in both cortex and thalamus were clearly identified, and the labeling pattern at P25 was identical to the adult (Fig. 3). PSD-95 was not ubiquitously expressed in neuronal subtypes. In somatosensory cortex, most labeled cells were pyramidal in shape with somata located in layers V-VI and long apical dendrites extending toward the surface (Fig. $3 A, B)$. Double immunofluorescent labeling revealed that GABA-immunopositive neurons in the cortex did not colocalize PSD-95 (Fig. 3 B, C). In somatosensory thalamus, a few lightly PSD-95-labeled neurons were found in the thalamic reticular nucleus (RTN) (Fig. 3D, arrow), which is exclusively GABAergic, but the majority of PSD-95immunolabeled neurons were found in the VP (Fig. 3D,E) and other dorsal thalamic nuclei, where the neuronal population is exclusively glutamatergic in the mouse. The trend for PSD-95 expression to be restricted to non-GABAergic neurons was observed in most brain areas examined (supplemental material, available at www.jneurosci.org). However, in some regions (i.e., substantia nigra), PSD-95 was expressed in a subset of GABA neurons (supplemental material, available at www.jneurosci.org).

\section{Synaptic localization of NR2A and} NR2B subunits at cortical and thalamic synapses during early postnatal development

To determine whether the overall cellular changes in NR2 subunit mRNA or protein, as determined by in situ hybridization, Western blot, or immunohistochemistry, were reflected in the synaptic localization, postembedding immunogold electron microscopy was used to reveal and quantify changes at morphologically identified cortical and thalamic synapses.

Layer IV of somatosensory cortex from P2, P9, P15, and P19 animals was selected for quantitative immunogold electron microscopic analysis. The majority of immunogold particles representing NR2A or NR2B subunits were associated with the PSDs of asymmetrical synapses and were rarely detected in presynaptic terminals (Fig. 4).

$N R 2 A$

At P2, the majority of cortical synapses exhibited immature features characterized by a low number of presynaptic vesicles and less prominent PSDs (Fig. 4A). Few NR2A immunogold particles were detected at PSDs of these immature synapses. After P2, the likelihood of detecting synapses with a high number of presynaptic vesicles and prominent PSDs significantly increased. Along with synaptic maturation, the number of NR2A immunogold particles at PSDs increased rapidly until P9, after which levels remained fairly constant $(3.8 \pm 1.4$ particles per PSD) (Fig. $4 B, E)$. After P15, synaptic NR2A levels increased again, reaching a peak at $\mathrm{P} 19$ ( $8.5 \pm 3.3$ particles per PSD) (Fig. $4 C-E)$, the latest age examined, and the mean number at P19 was significantly higher than P2 (Student's $t$ test, $p \leq 0.0001$ ). 


\section{NR2B}

In sharp contrast to NR2A, at P2, a significant number of NR2B particles were present at PSDs of immature cortical synapses $(2.3 \pm 0.5$ particles per PSD) (Fig. $4 F, G, J)$. The number of particles at each PSD remained fairly constant $(2.4 \pm 1.2$ particles per PSD) until P9 (Fig. $4 H, J$ ) and then progressively declined through P19 (1.2 \pm 0.5 particles per PSD; $p \leq 0.01$ compared with P2) (Fig. 4I,J), the latest age examined.

Thalamic samples containing the VP nucleus at P2, P4, P7, P9, P15, and P32 were also quantitatively examined by immunoelectron microscopy (Fig. 5).

\section{NR2A}

Ninety-five percent of immunogold labeling for NR2A was associated with PSDs of asymmetrical thalamic synapses (Fig. 5A$C)$. Approximately $5 \%$ of immunolabeling was detected in the cytoplasm of dendritic profiles (data not shown). Less than $1 \%$ of particles was found in presynaptic terminals and, in most cases, could not be traced in adjacent thin sections and was therefore considered as background labeling. Quantitatively, immunogold staining for NR2A was sparse from P2 to P4, and few particles were detected at PSDs $(0.2 \pm$ 0.5 particle per PSD) (Fig. $5 A, D$ ). From $\mathrm{P} 4$ to $\mathrm{P} 7$, the number of particles increased almost threefold (Fig. $5 B, D$ ). By P9, >10fold the number of immunogold particles at PSDs could be detected compared with P2 (2.8 \pm 1.8 particles per PSD) (Fig. $5 D, K)$, and similar values were measured at P15 (3.0 \pm 1.5 particles per PSD) (Fig. $5 C, D)$ and $\mathrm{P} 32(3.2 \pm 1.8$ particles per PSD $)$ (Fig. 5D). The most dramatic increase in synaptic NR2A occurred between P4 and P9 when levels increased more than fivefold (Student's $t$ test, $p \leq 0.0001$ ) (Fig. 5D).

\section{$N R 2 B$}

Consistent with the high cellular expression of NR2B at P2, a high number of NR2B gold particles were detected at PSDs of thalamic synapses $(3.3 \pm 1.6$ particles per PSD) (Fig. $5 E, F, J)$. From P4 to $\mathrm{P} 7$, the number of NR2B particles increased slightly, reaching a peak level at $\mathrm{P} 7(3.8 \pm 1.0$ particles per PSD) (Fig. $5 G, H, J)$. After P7, in sharp contrast to cellular NR2B expression levels, the number of NR2B particles at thalamic synapses began declining and was reduced by $>50 \%$ at P15 (1.9 \pm 0.9 particles per PSD; Student's $t$ test, $p \leq 0.007$ ) (Fig. 5I,J). Reduced synaptic NR2B was maintained at least through P32 (1.5 particles per PSD) (Fig. 5J).

\section{Extrasynaptic localization of NR2B}

Because synaptic expression of NR2B decreased, whereas the overall cellular expression remained constant, we determined whether NR2B subunits were redistributed to extrasynaptic sites at later ages. To do this, plasma membranes within 20-500 nm from PSD edge were examined for the presence of extrasynaptically localized immunogold particles using criteria outlined in Methods and Materials. Although some particles were found in $p \leq 0.01)$.
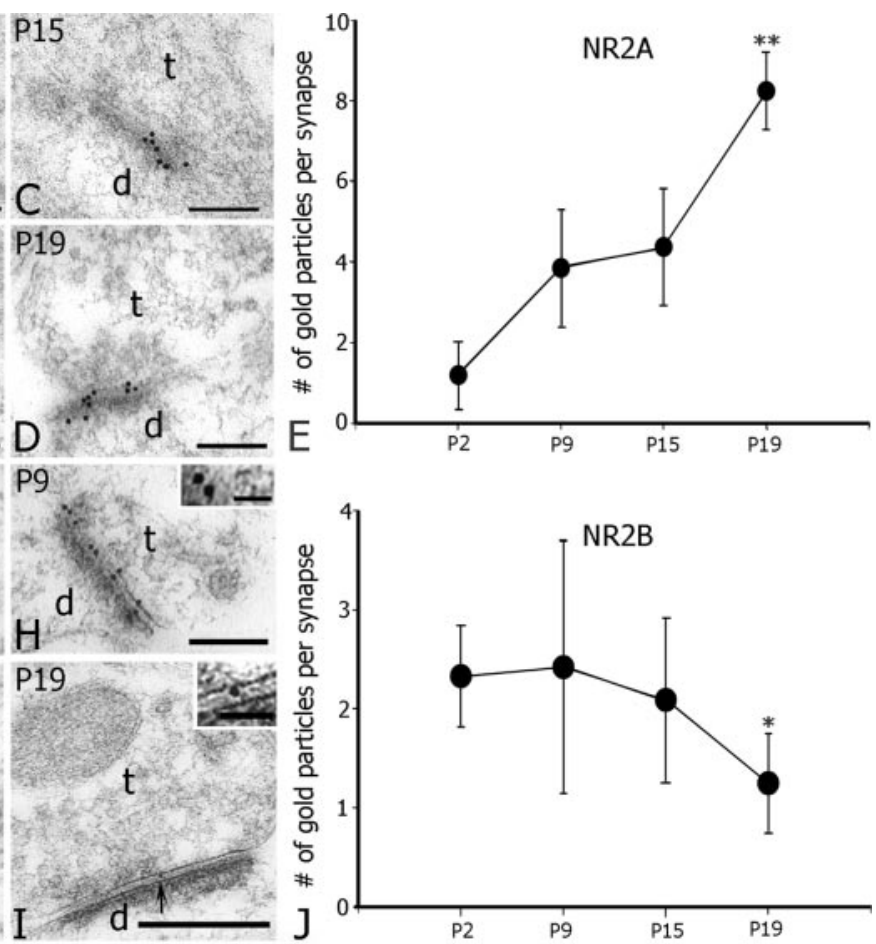

Figure 4. Synaptic localization of NR2A and NR2B subunits visualized by postembedding immunogold electron microscopy in layer IV of somatosensory cortex during postnatal development (P2-P19). A-D, Electron micrographs showing changes in the

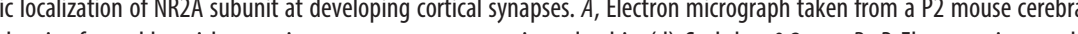
(mean \pm SD) at each PSD profile as a function of postnatal age. Note that ( Changes in the mean number of NR2B particles at single PSD profiles as a function of postnatal age are plotted. Note that the number of particles at single PSD profiles declines after P9. The difference between P2 and P19 is significant (Student's $t$ test;

the dendritic cytoplasm, no significant amount of immunogold particles was detected at extrasynaptic membranes. To determine whether this was attributable to the sensitivity of the postembedding immunogold technique, we performed two additional analyses of extrasynaptic NR2 receptors. First, we analyzed extrasynaptic labeling using a 2.5-fold higher primary antibody concentration. Second, we used decreasing concentrations of $\mathrm{NaCl}$ in the TBST buffer solution for immunogold labeling, which has been suggested for increasing the sensitivity of immunogold labeling (Y. He, W. G. M. Janssen, and J. H. Morrisson, personal communication). Both methods resulted in a significant enhancement in the membrane-associated labeling as well as an increase in the background staining. Despite the increased sensitivity, however, very few extrasynaptically localized NR2B gold particles were observed (data not shown). In addition to increasing the sensitivity of antibody labeling, we looked for extrasynaptically localized NR2B in serial sections from synapses used for quantitative analysis of synaptic NR2 labeling. A total of 20 immunolabeled cortical synapses at P19, stained for NR2B, were studied in serial sections. Although small clusters of NR2Bpositive gold particles were occasionally observed, they could not be traced in adjacent sections (supplemental material, available at 

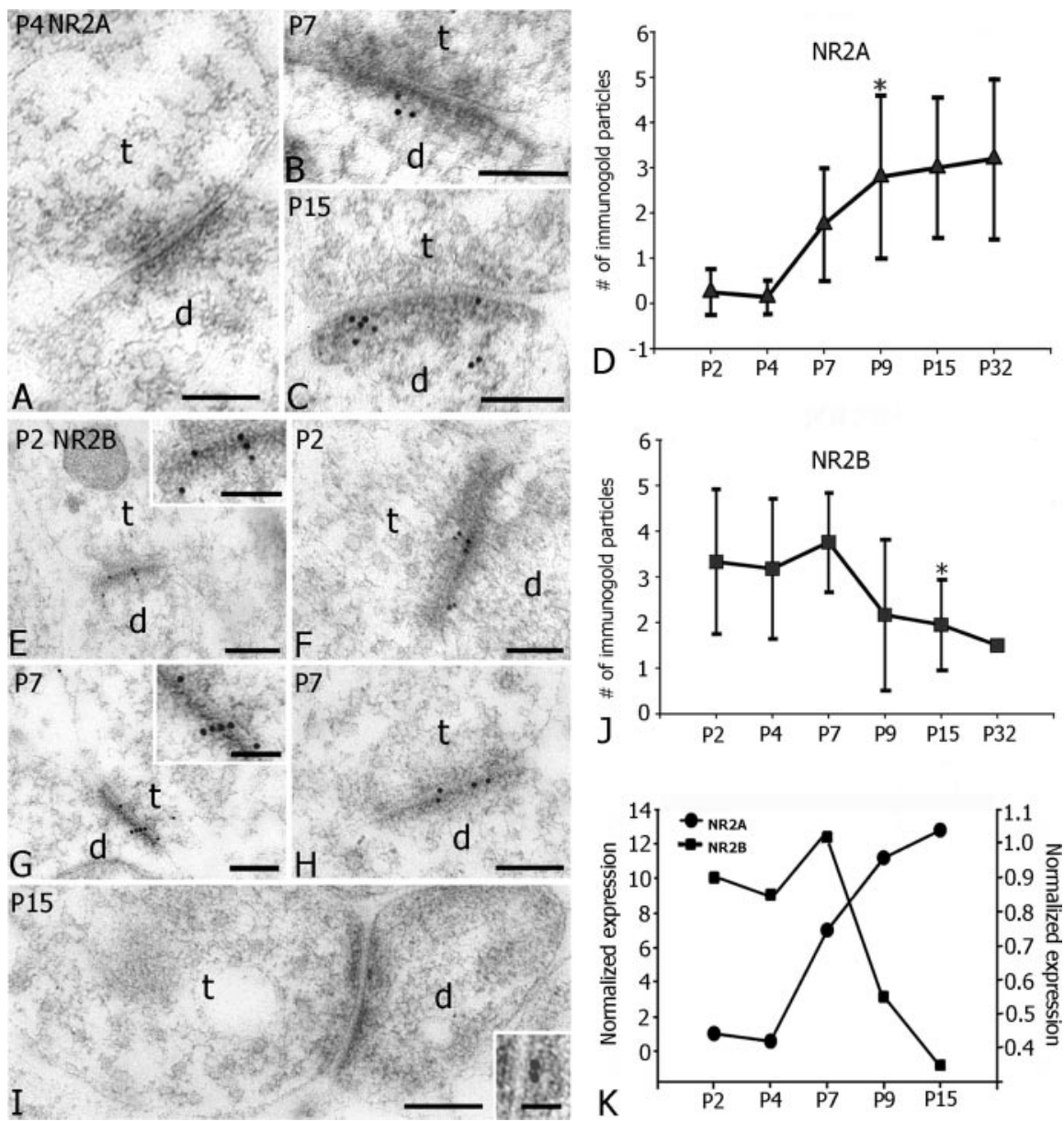

Figure 5. Synaptic localization of NR2A and NR2B subunits demonstrated by postembedding immunogold electron microscopy at developing synapses in VP nucleus of thalamus. $A-C$, Progressive changes in the synaptic distribution of NR2A subunit at developing thalamic synapses. $A$, Few, if any, NR2A immunogold particles are seen at PSDs of asymmetrical synapses at P4 $(A)$, but by P15 ( $C$, a number of NR2A gold particles are found concentrated at the PSD of an asymmetrical synapse formed by a terminal (t). Scale bars, $0.2 \mu \mathrm{m}$. D, Graph illustrating the increased number of NR2A particles at single PSD profiles of thalamic synapses as a function of postnatal age. A significant increase occurs between P4 and P9 (Student's $t$ test; $p \leq 0.001$ ). E-I, Electron micrographs showing synaptic localization of NR2B subunits at developing synapses in VP nucleus. At P2 $(E, F)$, NR2B immunogold particles are specifically associated with PSDs of thalamic synapses contacting dendritic profiles (d). Inset in $E$ is a highmagnification image showing immunogold particles associated with a PSD profile. At P7 $(G, H)$, electron micrographs show NR2B immunogold particles concentrated at the PSDs of asymmetrical synapses (t). By P15 (I), few gold particles are detected at thalamic PSDs. The inset in / shows a high-power image of two gold particles at a PSD profile. Scale bars: $E-I, 0.2 \mu \mathrm{m} ; E, G$, insets, $0.1 \mu \mathrm{m} ;$ I, inset, $0.05 \mu \mathrm{m}$. J, Graph showing the progressive change in the mean number of NR2B particles at single PSD profiles of thalamic synapses as a function of postnatal age; a significant decrease occurs from P7 to P15 (Student's $t$ test; $p \leq 0.001$ ). $K$, Graph showing changes in the normalized number of NR2A (filled black circle) and NR2B (filled black square) particles at thalamic synapses at different postnatal ages. The mean numbers of particles at each age is normalized to the mean numbers at P2. Note the reciprocal nature of changes in NR2A and NR2B subunits at single PSD profiles after P7.

www.jneurosci.org). In contrast, gold particles at PSDs of asymmetrical synapses could be readily traced in adjacent sections (supplemental material, available at www.jneurosci.org). For P15 and P19 VP samples, a total of eight labeled synapses were examined, and the results were similar to cortex (data not shown). Based on these observations, it seems that the amount of extrasynaptic NR2B is below detection using the methods used in this study.

\section{Synaptic localization of PSD-95}

To test whether developmental changes in synaptic NR2 expression were correlated with changes in its major synaptic binding partner, PSD-95, we examined the developmental localization of PSD-95 at cortical and thalamic synapses. The synaptic localiza- tion of PSD-95 differed from that of NR2 subunits. When single sections were examined, PSD-95 immunogold particles tended to form clusters at the core of the PSD profiles (Fig. $6 A, C$ ), in contrast to NR2A and NR2B, which were evenly distributed (Fig. 4). To test whether NR2A or NR2B and PSD-95 were colocalized at cortical synapses, double immunogold labeling with different sized particles $(10 \mathrm{~nm}$ particles for PSD-95, and 15 or $20 \mathrm{~nm}$ particles for NR2A or 2B) was used. Both NR2A and NR2B were closely associated with PSD-95 particles at the PSDs of cortical synapses (Fig. 6A, $B$ ).

The clustering of PSD-95 particles at PSD of thalamic synapses was even more pronounced compared with labeled cortical synapses (Fig. 7A-C). Quantitatively, at thalamic synapses, the number of PSD-95 immunogold particles was relatively low at P2 $(1.3 \pm 0.6$ particles per PSD) but increased more than twofold by P4 (3.8 \pm 1.9 particles per PSD) (Fig. $7 A, D)$. After P4, the number of PSD-95 particles remained constant at each PSD profile, at least through P32, the latest age examined $(3.0 \pm 1.5$ particles per PSD $)$ (Fig. 7B-E).

\section{Discussion}

This is the first correlative study in the mouse somatosensory system comparing the cellular and synaptic expression of NR2 subunits during a period of early postnatal development, critical for the maturation of thalamocortical circuitry (Crair and Malenka, 1995; Warren and Jones, 1997; Feldman et al., 1998). Our findings confirm morphologically that a switch in NMDAR subunit expression occurs at cortical and thalamic synapses during this developmental period. The major findings are, first, during early postnatal development, the cellular expression of NR2A increased from near background levels at P2 to adult levels by P15. In contrast, adult levels of cellular NR2B expression were already observed by $\mathrm{P} 2$ and, except for a transient increase at P7, remained fairly constant throughout early postnatal development. Thus, early in postnatal development, cellular NR2 expression is dominated by the NR2B subunit, although later, expression is a mix of both NR2A and NR2B subunits. This occurred in both cortex and thalamus indicating that NMDA receptors are under tight regulation in both regions. Second, consistent with changes in cellular expression, synaptic levels of NR2A increased gradually during early postnatal development. In contrast, despite relatively high cellular expression levels, synaptic NR2B decreased over the same time period. Third, PSD-95 was selectively localized to non-GABAergic neurons in many brain areas and invariably colocalized with NR2A and NR2B at cortical and thalamic synapses. However, temporally, the developmental regula- 

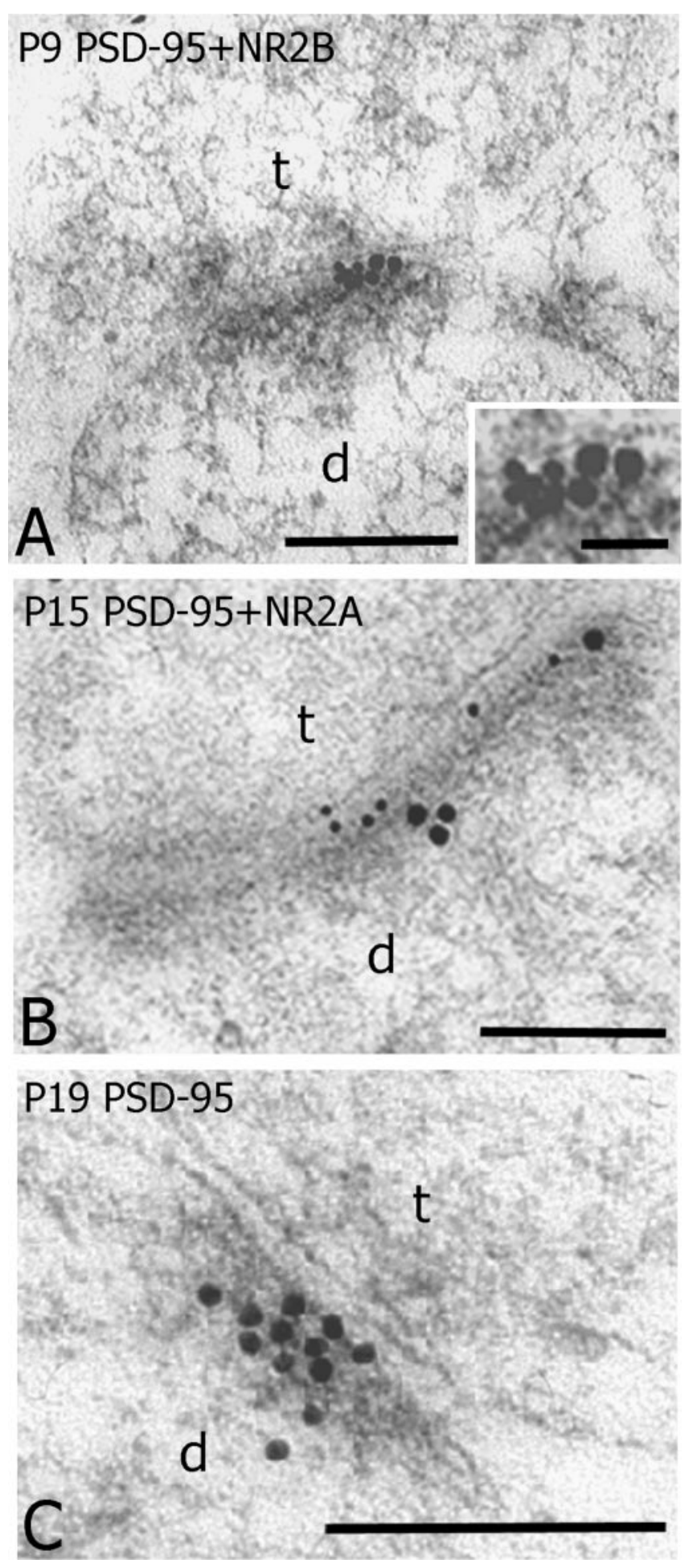

Figure 6. Synaptic colocalization of PSD-95 and NR2 subunits at developing synapses in layer IV of somatosensory cortex. A, An electron micrograph showing PSD-95 (small particles, 10 $\mathrm{nm}$ ) and NR2B (large particles, $15 \mathrm{~nm}$ ) colocalized at the PSD of an asymmetrical synapse (t) contacting a dendritic profile (d) at P9. B, PSD-95 (10 nm particles) and NR2A ( $20 \mathrm{~nm}$ particles) also colocalized at a PSD profile of an asymmetrical synapse (t) contacting dendritic profile (d) at P15. C, A cluster of PSD-95 particles concentrated at the PSD profile of an asymmetrical synapse at P19. Scale bars: $0.2 \mu \mathrm{m} ; A$, inset, $0.05 \mu \mathrm{m}$.

tion of synaptic PSD-95 did not correlate well with changes in NR2 subunit, suggesting that these changes occur independently.

PSD-95 is a major component of subcellular fractions enriched for excitatory (asymmetrical Type-I) synapses, closely as- sociates with NMDA receptor subunits, and modulates glutamate receptor expression at synapses (Kennedy, 1997; Garner et al., 2000; Tomita et al., 2001). Therefore, it may seem surprising that many GABAergic neurons, presumably expressing excitatory glutamate receptors, do not express PSD-95. However, the pattern of PSD-95 expression described herein is consistent with previous reports of PSD-95 protein (Cho et al., 1992; Hunt et al., 1996) and with the heterogeneous nature of PSD-95 mRNA expression throughout brain (Fukaya et al., 1999). The nonubiquitous nature of PSD-95 expression implies that it is not an absolute requirement for mature excitatory synaptic function. Other postsynaptic scaffolding proteins related to PSD-95 have been identified recently and may be selectively used at excitatory synapses to generate a diversity of PSD function not yet appreciated (Jo et al., 1999; Garner et al., 2000; Kennedy, 2000). This could account for the subtle rather than lethal phenotype resulting from a loss of PSD-95 (Migaud et al., 1998). This is also consistent with our observation that the formation of mature NR2 synapses is independent of PSD-95 expression.

\section{Molecular correlates of functional NR2 subunits}

These results are consistent with the view that a change in the predominant NR2 subunit expressed at developing excitatory synapses underlies the developmental changes in the biophysical properties of the NMDAR complex. NMDAR comprised of NR2A or NR2B are functionally different. Heterogonous cells coexpressing NR2B and the obligatory NR1 subunit are sensitive to the NR2B-specific antagonist ifenprodil and display relatively long-duration EPSC decay times (Stocca and Vicini, 1998). Replacing NR2B with NR2A removes ifenprodil sensitivity and shortens the decay time. Similar changes in NMDAR responses have been observed during early development. At thalamocortical synapses in the mouse somatosensory cortex, sensitivity to ifenprodil decreases significantly in the second postnatal week (after P7) (Barth and Malenka, 2001). A significant developmental decline in the duration of NMDA currents also occurs at thalamocortical synapses in visual and somatosensory cortex (Carmignoto and Vicini, 1992; Crair and Malenka, 1995). Our results demonstrate that these changes in NMDAR kinetics are the result of a physical change in the composition of predominant receptor subunits at developing synapses. Because NR2B cellular expression remained high, whereas synaptic expression was lost, we conclude that these changes are not simply the replacement of one subunit for another but involve a more complex mechanism.

\section{Mechanisms of NR2 switching}

Activity-dependent reciprocal changes in NR2 transcription has been suggested as a model for the observed regulation of NMDAR function (Fig. 8) (Feldman and Knudsen, 1998; Barria and Malinow, 2002; Sans et al., 2003). However, our findings are not consistent with changes in transcription levels as the principal mode for regulating altered synaptic NR2 expression. Although the developmental increase in synaptic NR2A was highly correlated with an enhancement in both cellular mRNA and protein expression, the synaptic decrease of NR2B was at odds with the constant level of cellular expression into adulthood (Zhong et al., 1995; Quinlan et al., 1999a; our study). This suggests that developmental changes in synaptic expression of NR2A and NR2B subunits are likely to occur through separate mechanisms and that the developmental reduction in synaptic NR2B expression occurs independent of transcriptional or translational changes. Similarly, independent regulation is observed in young hippocampal slice cultures where the synaptic insertion of NR2A is 

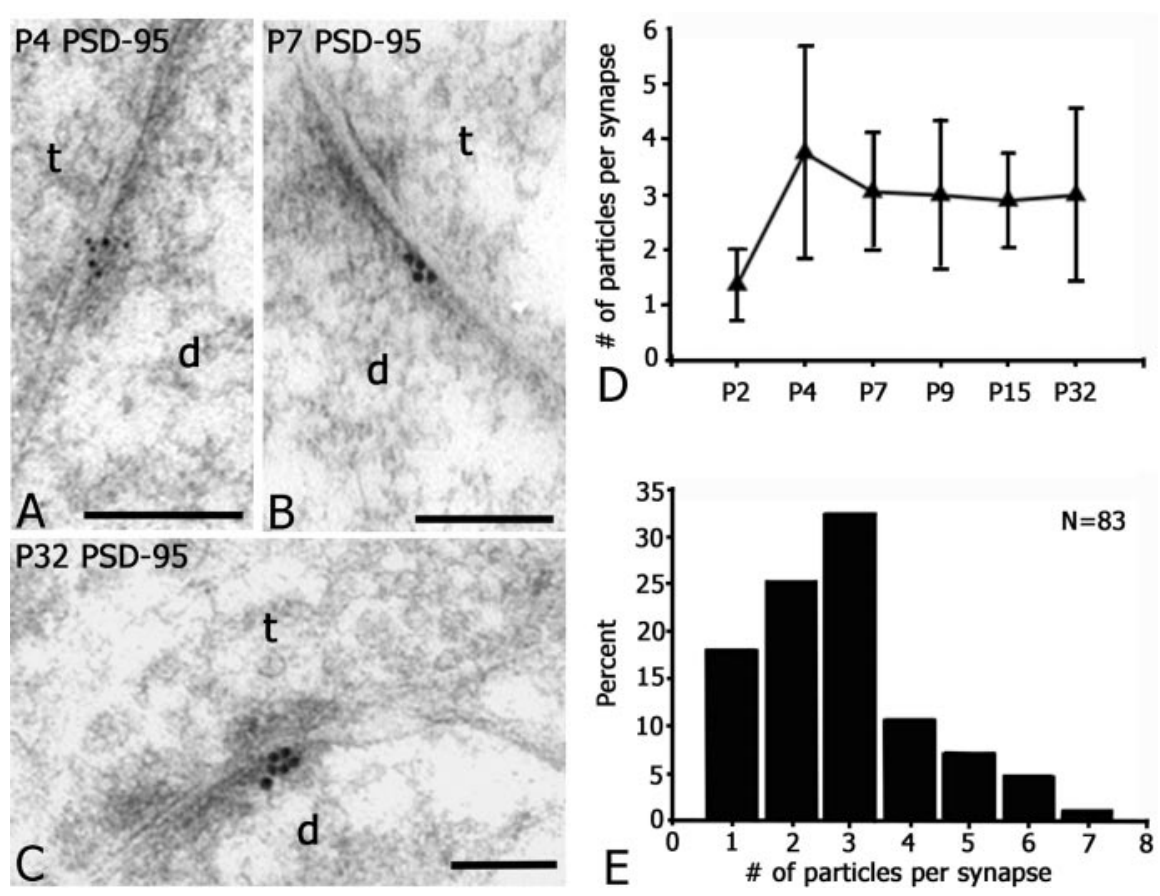

Figure 7. Developmental changes in the synaptic localization of PSD-95 in the VP nucleus of the thalamus. $A, B, A t P 4(A)$ and P7 (B), PSD-95 immunogold particles are concentrated at the core of PSD profiles of asymmetrical synapses. Scale bars, $0.1 \mu \mathrm{m}$. C, A similar concentration of PSD-95 immunogold particles is consistently found at the core of PSDs of asymmetrical synapses $(t)$ at P32. Scale bar, $0.1 \mu \mathrm{m}$. D, Graph showing changes in the mean number of PSD-95 immunogold particles (mean \pm SD) at single PSD profiles as a function of postnatal age. Note the dramatic increase in the mean particle number at $\mathrm{P} 4$ that remains relatively stable through P32. E, Bar graph showing the distribution of the mean number of PSD-95 immunogold particles at single PSD profiles of thalamic synapses at P32. Note that approximately two to three particles are localized at each single PSD profile $(n=83)$.

P2 Subunit "Switch"
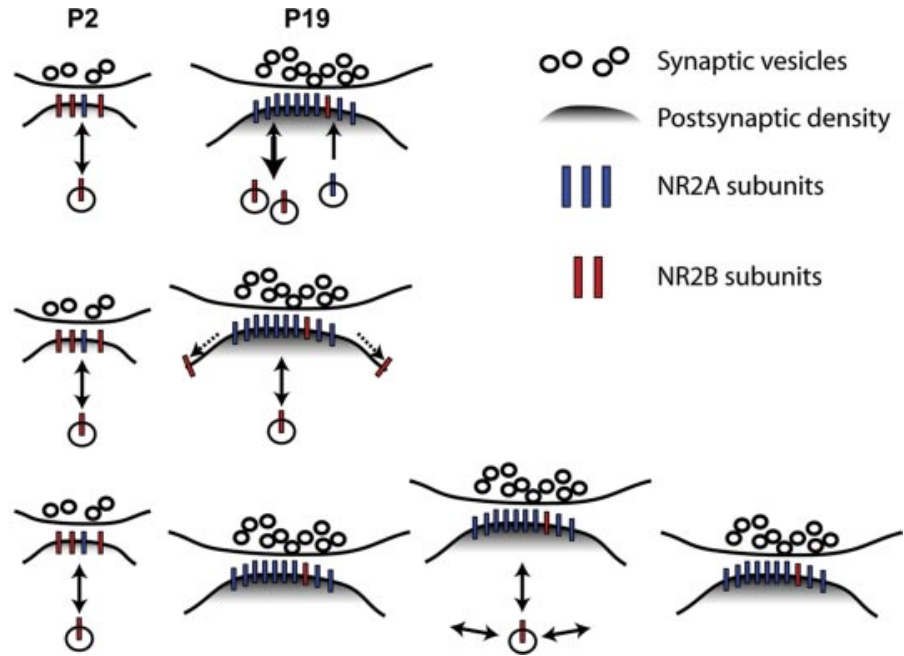

the visual cortex, visual experience during early postnatal development increased the synaptic expression of NR2A but not of $\mathrm{NR} 2 \mathrm{~B}$, and this was dependent on protein synthesis (Quinlan et al., 1999a,b). Similarly, we observed a developmental increase in synaptic expression of NR2A in the somatosensory cortex and thalamus that was highly correlated with developmental changes in its mRNA and protein levels. In contrast, the removal of NR2B from cortical and thalamic synapses occurred without significant changes in NR2B mRNA or protein expression at the cellular level.

What alternative mechanisms might govern the developmental changes in synaptic NR2B expression? An appealing hypothesis is that synaptic NR2B is displaced to extrasynaptic sites after the insertion of NR2A (Fig. 8). Evidence for an extrasynaptic pool of NR2B has been demonstrated in dissociated cortical and hippocampal neurons (Stocca and Vicini, 1998; Tovar and Westbrook, 1999) where clusters of NR2B were found at synaptic and extrasynaptic sites, whereas NR2A was exclusively localized at the core of synapses (Li et al., 1998). Also, a progressive decline in the sensitivity of the specific NR2B blocker, CP101,606, was detected with whole-cell patch clamp but not on excised membrane patches from the cell soma (Stocca and Vicini, 1998), implying a separate pool of NR2B-containing NMDA receptors. In the present study, we were unable to detect a significant pool of extrasynaptic NR2B subunits, which is not consistent with this model. It is conceivable, however, that the concentration of any extrasynaptic pool might be below the level of reliable detection by immunogold electron microscopy. For example, although they could not be traced in serial sections and therefore did not meet the criteria for inclusion, small clusters of extrasynaptically localized NR2B were observed (supplemental material, available at www.jneurosci.org). Also, in the present study, we focused mainly on extrasynaptic regions that were relatively loose to the PSD (20-500 nm away) and therefore may have missed clusters of NR2 subunits in other cellular compartments (e.g., the cell soma).

A second possible mechanism for the loss of synaptic NR2B is the dilution of the

- A schematic diagram summarizes three potential models for the switching of NR2A and NR2B subunits synapses. Subunit "Switch" (model 1) results from a dramatic increase in synaptic NR2A (short blue bars) and concomitan decrease in synaptic NR2B subunits (short red bars) caused by reciprocal changes in the expression of NR2 subunits. Extrasynaptic displacement (model 2) results in a progressive shift of NR2B subunits from synaptic sites to extrasynaptic sites accompanying an increase in NR2A at synapses. Redistribution (model 3) in which a dilution of synaptic NR2B subunits is caused by a developmental increase in synapse number with an increase in NR2A expression but without similar increases in NR2B cellular expression.

dependent on neuronal activity, whereas NR2B insertion is not (Barria and Malinow, 2002). Moreover, in these cultures, synaptic NR2A expression is tightly linked to its cellular expression, whereas the level of synaptic NR2B is independent of its cellular expression (Barria and Malinow, 2002). Sensory experience also differentially regulates NR2A and NR2B synaptic expression. In receptor subunit at synapses as postnatal synaptogenesis occurs (Fig. 8). From P4 to P16, in layer IV of mouse barrel cortex, there is a 10-fold increase in the number of excitatory synaptic contacts (DeFelipe et al., 1997). A marked increase in excitatory synaptic contacts coupled with the stable expression of NR2B and a constitutive level of synaptic turnover would decrease the density of 
synaptic NR2B subunits (Fig. 8). Significantly, in the present study, loss of synaptic NR2B was greatest between P9 and P19 in the cortex, a period exhibiting the highest rate of excitatory synapse generation (DeFelipe et al., 1997).

\section{Thalamic NR2 switching}

This is the first report of a developmental switch in synaptic NR2 subunit in the thalamus. A switch in synaptic NR2A and NR2B subunits at VP synapses suggests a similar developmental change in NMDAR-mediated excitatory postsynaptic responses occurs in thalamus as well as in cortex. From P1 through P16, a gradual decrease in the time constant of decay for NMDA-mediated EPSCs at corticothalamic synapses in VP, in vitro, has been reported previously (Golshani et al., 1998), and this may be a reflection of the developmental switch in NR subunit expression. Whether these synapses also lose their sensitivity to ifenprodil is unknown. However, a developmental decrease in ifenprodil sensitivity was observed during the critical period of development in the ferret lateral geniculate nucleus (Ramoa and Prusky, 1997). The timing of NR2A/NR2B subunit switching is different at thalamic and cortical synapses; occurring approximately 2 d earlier in VP (P7) than cortex (P9) (compare Figs. $4 J$ and $5 J$ ). Such a delay may be important for the maturation of thalamocortical circuitry. The longer duration and larger amplitude characteristic of NR2Bdominated currents is likely to result in greater $\mathrm{Ca}^{2+}$ entry through NMDA channels at developing synapses thereby facilitating long-term plasticity of synaptic responses and/or promote the establishment and stabilization of thalamocortical circuitry (Constantine-Paton and Cline, 1998; Crair, 1999; Cull-Candy et al., 2001).

\section{NR2B synaptic loss and developmental plasticity}

A switch in the subunit expression of NMDARs at synapses has been suggested as a mechanism for establishing the timing of the critical period for developmental plasticity. Not only are the biophysical changes in NMDAR function that occur during development temporally linked to critical periods, but there is a potentially dramatic change in $\mathrm{Ca}^{2+}$ signaling brought about by the faster kinetics, and intracellular $\mathrm{Ca}^{2+}$ levels are critical for plasticity (Feldman and Knudsen, 1998). Despite this, no direct link between changes in NMDAR properties and plasticity has been established, and in fact, mice devoid of NR2A have normal critical period timing, raising doubt as to the validity of this argument (Lu et al., 2001). Given that the mechanism of synaptic expression for NR2A and NR2B could be different (see above), the timing of the critical development period may depend on one and not the other. This fits well with the recent observation that two opposing forms of synaptic plasticity, long-term potentiation and long-term depression, are differentially mediated by NR2A and 2B, respectively, in the hippocampus (Liu et al., 2004). In this regard, it is interesting to note that while NR2A synaptic insertion continues beyond the end of the critical period (P2-P7, mouse somatosensory cortex) (Crair and Malenka, 1995; Lu et al., 2001), the onset of NR2B removal from synapses coincides with the close of the critical period (Figs. $4 J, 5 J$ ). A similar coincidence was recently reported in ferret visual cortex (Erisir and Harris, 2003), raising the possibility that the loss of a critical mass of NR2B at synapses triggers the close of the critical period. Because transgenic knock-out of NR2B is lethal (Kutsuwada et al., 1996), it will be interesting to see whether conditional NR2B knock-out animals, with restrictive loss of NR2B to cerebral cortex and/or thalamus, have disrupted critical period timing.

\section{References}

Akbarian S, Sucher NJ, Bradley D, Tafazzoli A, Trinh D, Hetrick WP, Potkin SG, Sandman CA, Bunney Jr WE, Jones EG (1996) Selective alterations in gene expression for NMDA receptor subunits in prefrontal cortex of schizophrenics. J Neurosci 16:19-30.

Barria A, Malinow R (2002) Subunit-specific NMDA receptor trafficking to synapses. Neuron 35:345-353.

Barth AL, Malenka RC (2001) NMDAR EPSC kinetics do not regulate the critical period for LTP at thalamocortical synapses. Nat Neurosci 4:235-236.

Bear MF, Kleinschmidt A, Gu QA, Singer W (1990) Disruption of experience-dependent synaptic modifications in striate cortex by infusion of an NMDA receptor antagonist. J Neurosci 10:909-925.

Carmignoto G, Vicini S (1992) Activity-dependent decrease in NMDA receptor responses during development of the visual cortex. Science 258:1007-1011.

Cho KO, Hunt CA, Kennedy MB (1992) The rat brain postsynaptic density fraction contains a homolog of the Drosophila discs-large tumor suppressor protein. Neuron 9:929-942.

Constantine-Paton M, Cline HT (1998) LTP and activity-dependent synaptogenesis: the more alike they are, the more different they become. Curr Opin Neurobiol 8:139-148.

Crair MC (1999) Neuronal activity during development: permissive or instructive? Curr Opin Neurobiol 9:88-93.

Crair MC, Malenka RC (1995) A critical period for long-term potentiation at thalamocortical synapses. Nature 375:325-328.

Cull-Candy S, Brickley S, Farrant M (2001) NMDA receptor subunits: diversity, development and disease. Curr Opin Neurobiol 11:327-335.

DeFelipe J, Marco P, Fairen A, Jones EG (1997) Inhibitory synaptogenesis in mouse somatosensory cortex. Cereb Cortex 7:619-634.

Erisir A, Harris JL (2003) Decline of the critical period of visual plasticity is concurrent with the reduction of NR2B subunit of the synaptic NMDA receptor in layer 4. J Neurosci 23:5208-5218.

Feldman DE, Knudsen EI (1998) Experience-dependent plasticity and the maturation of glutamatergic synapses. Neuron 20:1067-1071.

Feldman DE, Nicoll RA, Malenka RC, Isaac JTR (1998) Long-term depression at thalamocortical synapses in developing rat somatosensory cortex. Neuron 21:347-357.

Flint AC, Maisch US, Weishaupt JH, Kriegstein AR, Monyer H (1997) NR2A subunit expression shortens NMDA receptor synaptic currents in developing neocortex. J Neurosci 17:2469-2476.

Fukaya M, Ueda H, Yamauchi K, Inoue Y, Watanabe M (1999) Distinct spatiotemporal expression of mRNAs for the PSD-95/SAP90 protein family in the mouse brain. Neurosci Res 33:111-118.

Garner CC, Nash J, Huganir RL (2000) PDZ domains in synapse assembly and signalling. Trends Cell Biol 10:274-280.

Golshani P, Warren RA, Jones EG (1998) Progression of change in NMDA, non-NMDA, and metabotropic glutamate receptor function at the developing corticothalamic synapse. J Neurophysiol 80:143-154.

Hunt CA, Schenker LJ, Kennedy MB (1996) PSD-95 is associated with the postsynaptic density and not with the presynaptic membrane at forebrain synapses. J Neurosci 16:1380-1388.

Iwasato T, Erzurumlu RS, Huerta PT, Chen DF, Sasaoka T, Ulupinar E, Tonegawa S (1997) NMDA receptor-dependent refinement of somatotopic maps. Neuron 19:1201-1210.

Jo K, Derin R, Li M, Bredt DS (1999) Characterization of MALS/Velis-1, -2, and -3: a family of mammalian LIN-7 homologs enriched at brain synapses in association with the postsynaptic density-95/NMDA receptor postsynaptic complex. J Neurosci 19:4189-4199.

Katz LC, Shatz CJ (1996) Synaptic activity and the construction of cortical circuits. Science 274:1133-1138.

Kennedy MB (1997) The postsynaptic density at glutamatergic synapses. Trends Neurosci 20:264-268.

Kennedy MB (2000) Signal-processing machines at the postsynaptic density. Science 290:750-754.

Kutsuwada T, Sakimura K, Manabe T, Takayama C, Katakura N, Kushiya E, Natsume R, Watanabe M, Inoue Y, Yagi T, Aizawa S, Arakawa M, Takahashi T, Nakamura Y, Mori H, Mishina M (1996) Impairment of suckling response, trigeminal neuronal pattern formation, and hippocampal LTD in NMDA receptor epsilon 2 subunit mutant mice. Neuron 16:333-344.

Li JH, Wang YH, Wolfe BB, Krueger KE, Corsi L, Stocca G, Vicini S (1998) 
Developmental changes in localization of NMDA receptor subunits in primary cultures of cortical neurons. Eur J Neurosci 10:1704-1715.

Li Y, Erzurumlu RS, Chen C, Jhaveri S, Tonegawa S (1994) Whisker-related neuronal patterns fail to develop in the trigeminal brainstem nuclei of NMDAR1 knockout mice. Cell 76:427-437.

Liu LD, Wong TP, Pozza MF, Lingenhoehl K, Wang YS, Sheng M, Auberson YP, Wang YT (2004) Role of NMDA receptor subtypes in governing the direction of hippocampal synaptic plasticity. Science 304:1021-1024.

Liu XB, Bolea S, Golshani P, Jones EG (2001) Differentiation of corticothalamic and thalamocortical synapses on mouse reticular nucleus neurons by EPSC amplitude and AMPA receptor subunit composition. Thalamus Relat Syst 1:15-29.

Liu XB, Murray KD, Nguyen P, Jones EG (2002) Change in expression and synaptic localization of NMDA receptor 2 subunits and PSD-95 in mouse thalamus and cerebral cortex during postnatal development. Soc Neurosci Abstr 28:731.15.

Lu HC, Gonzalez E, Crair MC (2001) Barrel cortex critical period plasticity is independent of changes in NMDA receptor subunit composition. Neuron 32:619-634.

Matsubara A, Laake JH, Davanger S, Usami S, Ottersen OP (1996) Organization of AMPA receptor subunits at a glutamate synapse: a quantitative immunogold analysis of hair cell synapses in the rat organ of Corti. J Neurosci 16:4457-4467.

McBain CJ, Mayer ML (1994) N-methyl-D-aspartic acid receptor structure and function. Physiol Rev 74:723-760.

Migaud M, Charlesworth P, Dempster M, Webster LC, Watabe AM, Makhinson M, He Y, Ramsay MF, Morris RG, Morrison JH, O’Dell TJ, Grant SG (1998) Enhanced long-term potentiation and impaired learning in mice with mutant postsynaptic density-95 protein. Nature 396:433-439.

Munoz A, Woods TM, Jones EG (1999) Laminar and cellular distribution of AMPA, kainate, and NMDA receptor subunits in monkey sensory-motor cortex. J Comp Neurol 407:472-490.

Quinlan EM, Olstein DH, Bear MF (1999a) Bidirectional, experiencedependent regulation of $\mathrm{N}$-methyl-D-aspartate receptor subunit composition in the rat visual cortex during postnatal development. Proc Natl Acad Sci USA 96:12876-12880.

Quinlan EM, Philpot BD, Huganir RL, Bear MF (1999b) Rapid, experiencedependent expression of synaptic NMDA receptors in visual cortex in vivo. Nat Neurosci 2:352-357.

Ramoa AS, Prusky G (1997) Retinal activity regulates developmental switches in functional properties and ifenprodil sensitivity of NMDA re- ceptors in the lateral geniculate nucleus. Brain Res Dev Brain Res 101:165-175.

Rema V, Armstrong-James M, Ebner FF (1998) Experience-dependent plasticity of adult rat $\mathrm{S} 1$ cortex requires local NMDA receptor activation. J Neurosci 18:10196-10206.

Roberts EB, Ramoa AS (1999) Enhanced NR2A subunit expression and decreased NMDA receptor decay time at the onset of ocular dominance plasticity in the ferret. J Neurophysiol 81:2587-2591.

Sans N, Prybylowski K, Petralia RS, Chang K, Wang YX, Racca C, Vicini S, Wenthold RJ (2003) NMDA receptor trafficking through an interaction between PDZ proteins and the exocyst complex. Nat Cell Biol 5:520-530.

Schlaggar BL, Fox K, O’Leary DD (1993) Postsynaptic control of plasticity in developing somatosensory cortex. Nature 364:623-626.

Sheng M, Sala C (2001) PDZ domains and the organization of supramolecular complexes. Annu Rev Neurosci 24:1-29.

Stocca G, Vicini S (1998) Increased contribution of NR2A subunit to synaptic NMDA receptors in developing rat cortical neurons. J Physiol (Lond) 507:13-24.

Sucher NJ, Akbarian S, Chi CL, Leclerc CL, Awobuluyi M, Deitcher DL, Wu MK, Yuan JP, Jones EG, Lipton SA (1995) Developmental and regional expression pattern of a novel NMDA receptor-like subunit (NMDAR-L) in the rodent brain. J Neurosci 15:6509-6520.

Tomita S, Nicoll RA, Bredt DS (2001) PDZ protein interactions regulating glutamate receptor function and plasticity. J Cell Biol 153:F19-F24.

Tovar KR, Westbrook GL (1999) The incorporation of NMDA receptors with a distinct subunit composition at nascent hippocampal synapses in vitro. J Neurosci 19:4180-4188.

Townsend M, Yoshii A, Mishina M, Constantine-Paton M (2003) Developmental loss of miniature $\mathrm{N}$-methyl-D-aspartate receptor currents in NR2A knockout mice. Proc Natl Acad Sci USA 100:1340-1345.

Warren RA, Jones EG (1997) Maturation of neuronal form and function in a mouse thalamo-cortical circuit. J Neurosci 17:277-295.

Wenthold RJ, Prybylowski K, Standley S, Sans N, Petralia RS (2003) Trafficking of NMDA receptors. Annu Rev Pharmacol Toxicol 43:335-358.

Wong HK, Liu XB, Matos MF, Chan SF, Perez-Otano I, Boysen M, Cui J, Nakanishi N, Trimmer JS, Jones EG, Lipton SA, Sucher NJ (2002) Temporal and regional expression of NMDA receptor subunit NR3A in the mammalian brain. J Comp Neurol 450:303-317.

Zhong J, Carrozza DP, Williams K, Prittchett DB, Molinoff P (1995) Expression of messenger-RNAs encoding subunits of the NMDA receptor in developing rat brain. J Neurochem 64:531-539. 